\title{
How to Predict Exacerbations and Hospital Admissions in Stable COPD Outpatients?
}

\author{
Francesco Pistelli Giovanni Viegi \\ Cardiac and Thoracic Department University and Hospital of Pisa, and Institute of Clinical Physiology of the National \\ Research Council, Pisa, Italy
}

The incidence, morbidity and mortality from chronic obstructive pulmonary disease (COPD) are rising. While the diagnosis of COPD by general practitioners (GPs) is underestimated [1,2], COPD will be the fourth among the diseases that will contribute to the global burden of disease by 2020 , preceded by ischemic heart disease, unipolar major depression and cerebrovascular disease, respectively [3]. Moreover, prevalence rates of respiratory symptoms associated with COPD are relatively high $[1,2$, 4] and COPD is at present a major cause of frequent use of both general practice and hospital services in Europe $[5,6]$.

In order to standardize the assessment and management of COPD, in the last few years a number of national and international respiratory societies have published guidelines on diagnosis and care of COPD patients [1, 46]. As COPD is a chronic, slowly progressive and largely irreversible disorder, medical interventions of primary, secondary and tertiary prevention have been particularly recommended. Further, due to the natural course of the COPD, characterized by recurrent acute exacerbations and hospital admissions, shared care between GPs and hospital doctors seems to be the recommended way to follow up such patients. Epidemiological studies play a central role in identifying risk factors for COPD that can be usefully utilized in preventive clinical interventions in the general practice setting.

\begin{tabular}{ll}
\hline KARGER & ( ) 2000 S. Karger AG, Basel \\
0025-7931/00/0675-0491\$17.50/0 \\
$\begin{array}{l}\text { Fax +4161306 12 34 } \\
\begin{array}{l}\text { E-Mail karger@karger.ch } \\
\text { www.karger.com }\end{array}\end{array}$ & $\begin{array}{l}\text { Accessible online at: } \\
\text { www.karger.com/journals/res }\end{array}$
\end{tabular}

In the current issue of Respiration, Miravitlles et al. [7] report the results of a multiple logistic regression analysis, aimed at estimating the probability of having either frequent exacerbations or hospital admissions in outpatients with stable COPD.

Reduced forced expiratory volume in $1 \mathrm{~s}\left(\mathrm{FEV}_{1}\right)$ values were found to increase the risk for the two outcomes of the study, as expected. However, while those patients with chronic mucus hypersecretion and older age had an increased likelihood of two or more exacerbations per year, those with comorbidity - including cardiac insufficiency, ischemic heart disease and diabetes - were more likely to have hospital admissions.

These results confirm the importance of the respiratory function level in affecting the course of COPD, and, thus, the usefulness of a frequent spirometric follow-up of these patients.

However, the finding of chronic mucus hypersecretion as predictor of acute exacerbations is particularly interesting. Results from longitudinal epidemiological surveys have previously shown an association of chronic mucus hypersecretion with $\mathrm{FEV}_{1}$ decline, and subsequent hospitalization because of COPD [8]. Although international clinical guidelines do not strictly recommend mucokinetic agents in the treatment of COPD, they are used in clinical practice in some European countries. Possibly, in the light of such new epidemiological evidence, the role of

\footnotetext{
Francesco Pistelli, MD

CNR Institute of Clinical Physiology, Via Trieste 41

I-56126 Pisa (Italy)

Tel. +39050 502031/913632, Fax +39050503596

E-Mail Francesco.Pistelli@ifc.pi.cnr.it
} 
mucokinetic agents in the treatment of COPD should be further explored. Indeed, a large multicenter placebo-controlled study demonstrated symptomatic benefits and a significant reduction of the mean duration of acute exacerbations, in patients with stable chronic obstructive bronchitis treated with iodinated glycerol [9].

The experimental design adopted in the study of Miravitlles et al. [7] points out the usefulness of standardized recording of clinical data in the general practice setting, insofar as it allows the identification of risk factors and the application of coded definitions of disease. Operationally, such a methodology has both clinical and socioeconomic important implications. Predicting the risk for recurrent exacerbations or hospital admissions, by means of easily obtainable information, allows GPs to identify those COPD patients in the stable phase who need closer follow-up and preventive interventions. This can reduce the costs of treatment and improve the quality and expectancy of life in COPD patients.

\section{References}

1 Siafakas NM, Vermeire P, Pride NB, Paoletti P, Gibson J, Howard P, Yernault JC, Decramer M, Higenbottam T, Postma DS, Rees J, on behalf of the Task Force: Optimal assessment and management of chronic obstructive pulmonary disease. Eur Respir J 1995;8:13981420.

2 Viegi G, Pedreschi M, Baldacci S, Chiaffi L, Pistelli F, Modena P, Vellutini M, Di Pede F, Carrozzi L: Prevalence rates of respiratory symptoms and diseases in general population samples of North and Central Italy. Int J Tuberc Lung Dis 1999;3:1034-1042.

3 Murray CLJ, Lopez AD: Evidence-based health policy - Lessons from the Global Burden of Disease Study. Science 1996;274:740743.
4 American Thoracic Society: Standards for the diagnosis and care of patients with chronic obstructive pulmonary disease. Am J Respir Crit Care Med 1995;152:S77-S120.

5 British Thoracic Society: BTS guidelines for the management of chronic obstructive pulmonary disease. Thorax 1997;52(suppl 5):1-28.

6 Laitinen LA, Koskela K: Chronic bronchitis and chronic obstructive pulmonary disease: Finnish National Guidelines for Prevention and Treatment 1998-2007. Respir Med 1999; 93:297-332.
7 Miravitlles M, Guerrero T, Mayordomo C, Sánchez-Agudo L, Nicolau F, Segú JL: Factors associated with increased risk of exacerbation and hospital admission in a cohort of ambulatory COPD patients: A multiple logistic regression analysis. Respiration 2000;67:495-501.

8 Vestbo J, Prescott E, Lange P: Association of chronic mucus hypersecretion with $\mathrm{FEV}_{1}$ decline and chronic obstructive pulmonary disease morbidity. Copenhagen City Heart Study Group. Am J Respir Crit Care Med 1996;153: 1530-1535.

9 Petty TL: The National Mucolytic Study. Results of a randomized, double-blind, placebocontrolled study of iodinated glycerol in chronic obstructive bronchitis. Chest 1990;97: 75-83. 